\title{
Effects of climatological parameters on the outbreak spread of COVID-19 in highly affected regions of Spain
}

\author{
Khurram Shahzad $^{1} \cdot$ Umer Shahzad $^{2}$ (D) Najaf Iqbal $^{3} \cdot$ Farrukh Shahzad $^{4} \cdot$ Zeeshan Fareed $^{5}$
}

Received: 1 May 2020 / Accepted: 17 August 2020 / Published online: 22 August 2020

(C) Springer-Verlag GmbH Germany, part of Springer Nature 2020

\begin{abstract}
The coronavirus (COVID-19) pandemic is infecting the human population, killing people, and destroying livelihoods. This research sought to explore the associations of daily average temperature (AT) and air quality $\left(\mathrm{PM}_{2.5}\right)$ with the daily new cases of COVID-19 in the top four regions of Spain (Castilla y Leon, Castilla-La Mancha, Catalonia, and Madrid). To this end, the authors employ Pearson correlation, Spearman correlation, and robust panel regressions to quantify the overall co-movement between temperature, air quality, and daily cases of COVID-19 from 29 February to 17 July 2020. Overall empirical results show that temperature may not be a determinant to induce COVID-19 spread in Spain, while the rising temperature may reduce the virus transmission. However, the correlation and regression findings illustrate that air quality may speed up the transmission rate of COVID-19. Our findings are contrary to the earlier studies, which show a significant impact of temperature in raising the COVID-19 spread. The conclusions of this work can serve as an input to mitigate the rapid spread of COVID-19 in Spain and reform policies accordingly.
\end{abstract}

Keywords COVID-19 $\cdot$ Temperature $\cdot$ Air quality $\cdot$ Spain $\cdot$ Spearman correlation

\footnotetext{
Highlights

- The association between temperature, air quality, and COVID-19 in Spain is examined.

- The study applied Pearson correlation, Spearman correlation, and panel data regressions on highly affected regions of Spain.

- Temperature may not induce the COVID-19 outbreak in Spain.

- Air quality tends to have positive association with COVID-19 in the top four regions of Spain (Castilla y Leon, Castilla-La Mancha, Catalonia, and Madrid).
}

Responsible Editor: Philippe Garrigues

Umer Shahzad

Shehzad-umer@hotmail.com

Khurram Shahzad

khurrams.khurram@gmail.com

Najaf Iqbal

najaf_iqbal@live.com

Farrukh Shahzad

farrukh.hailian@gmail.com

Zeeshan Fareed

zeeshanfareed@hotmail.com
1 Key Laboratory of Resource Biology and Biotechnology in Western China, Ministry of Education, College of Life Sciences, Northwest University, Xi'an, People's Republic of China

2 School of Statistics and Applied Mathematics, Anhui University of Finance and Economics, Bengbu 233030, People's Republic of China

3 School of Finance, Anhui University of Finance and Economics, Bengbu 233030, People's Republic of China

4 School of Economics and Management, Guangdong University of Petrochemical Technology, Maoming, Guangdong, People's Republic of China

5 School of Business, Huzhou University, Huzhou City, Zhejiang, Province, People's Republic of China 


\section{Introduction}

A novel coronavirus disease (COVID-19) epidemic was first reported in Wuhan (China) in December 2019, which spread quickly around the globe (Anderson et al. 2020; Li et al. 2020; Gorbalenya 2020; Wu et al. 2020a). The transmission of viruses can be affected by many factors, including climate conditions (such as temperature, air quality, and humidity), populated areas, and healthcare quality (Wang et al. 2020). Therefore, understanding the relationship between climatic variation, the air quality of a country, and the transmission of COVID-19 is key to playing in the fight against the virus SARS-CoV-2. The two main factors include high temperature and humidity, directly correlated with the spreading of COVID-19 in any region (Wang et al. 2020). However, COVID-19 presents similar patterns in terms of spread rate as compared with the global spread of the Spanish Flu pandemic in 1919 (which affected hundreds of millions of people) and an outbreak of 2002-2003, severe acute respiratory syndrome (SARS) (3.5\% for COVID-19 and 11\% for SARS).

The climatological parameters could affect the virus spread via various channels. For example, the temperature and air quality level may increase or decrease the risk, survival period of the virus, transmission rate, and virus life in the air or surface. Hence, the sensitivity analysis of climatology parameters on COVID-19 infection rate is essential to ensure the survival of human beings (Jahangiri et al. 2020). To forecast the fast and slow down the pandemic and end time, it is necessary to understand the relationship between the transmission of COVID-19 and weather (extreme hot and cold conditions). For example, a respiratory disease influenza outbreak spreads quickly in winter conditions (Lowen et al. 2007; Tamerius et al. 2013). Few of the recent works reported the evidence that transmission of influenza decreased in high temperature and humidity (Shaman and Kohn 2009; Lipsitch and Viboud 2009; Steel et al. 2011; Park et al. 2019). Two conditions help to spread the infectious disease; first, dry air and respiratory droplets contain the longer airborne duration of the influenza virus and more stable in cold temperature (Lowen and Steel 2014; Tellier 2009). Second, due to the weak immune system of hosts in cold and dry weather, the virus has been susceptible to effect quickly to the hosts (Eccles 2002; Kudo et al. 2020).

The variables that affect the survival and contagion of the virus SARS involve optimal temperature, humidity, and wind velocity (Yuan et al. 2006). In this regard, the clinic symptoms of critically ill patients infected with COVID-19 are probably similar to those of SARS and MERS (Wang et al. 2020). The first reports showed that the contagion of the virus was limited in spreading from people to people (Chen et al. 2020) and can be able to transmit through the air (Mostafa et al. 2020). A study on influenza disease resulted that temperature and humidity are the leading cause of disease outbreak in Korea, and a significant positive association was observed for diurnal temperature range (DTR) (Park et al. 2019). In mid-March, Chinese researchers indicated that there is a correlation between meteorological factors (e.g., temperature, humidity) and COVID-19 outbreak (Oliveiros et al. 2020; Wang et al. 2020). Climate variables, e.g., temperature variation and air quality, can also be a direct cause of biological interactions between the SARS virus and humans (Yuan et al. 2006). Therefore, we assume that the weather conditions might also contribute to the spread of COVID-19.

Spain is located in southwestern Europe, with the capital city of Madrid, situated in the middle of Spain. The first case of COVID-19 in Spain was recorded on 31 January 2020, and now it is in the top ten countries with the highest COVID-19 cases with 260,555 confirmed cases as of 18 July 2020 (Ministry of Health Spain 2020).

Figure 1a illustrates the overall COVID-19 outlook with daily new cases, deaths, cases per million, and deaths per million in Spain. According to the reports of the World Health Organization and Spain authorities, the major affected areas of Spain are Madrid, Catalonia, Castilla-La Mancha, and Castilla y Leon respectively until 17 July 2020 (Fig. 2). According to World Health Orgnization records, there are more than 22 million confirmed pateints and approximately 0.8 million fatiliites globally till 21 August 2020 caused from COVID-19 (WHO 2020). (WHO 2020; report 180).

This research work joins the strand of few recent works, which also argued that COVID-19 has correlation relationships with temperature, air quality, and other weather conditions (Fareed et al. 2020; Iqbal et al. 2020; Tosepu et al. 2020). The mentioned studies argued that the SARS outbreak in 2003, in Guangdong, ended with the rise in temperature (Wang et al. 2020). Temperature, air quality, and humidity were documented to be practical factors in the spread of SARS disease. Few of the recent works suggested that COVID-19 patients might be similar to those of SARS and MERS (Wang et al. 2020; Shi et al. 2020). More recently, it was suggested that viruses could be transmitted by several factors, including climatic conditions (such as temperature, air quality, and humidity) and population density (Dalziel et al. 2018). The extreme weather conditions that accompany long-term climate variations may also contribute to the spread of the West Nile virus in the USA and Europe (Epstein 2001). The average temperature of Spain is around $57^{\circ} \mathrm{F}\left(\sim 14^{\circ} \mathrm{C}\right)$ year-round. Figure $3 \mathrm{a}$ shows the temperature difference between different regions of Spain. Recent studies on COVID-19 situation in China and Iran suggested that the low temperature and absolute humidity may also be essential factors of COVID-19 outbreak and mortality rate (Yueling et al. 2018; Mohsen et al. 2020). The discussion, as mentioned earlier, guides us that research on climate change and COVID-19 is still limited, and this research will contribute to an effort to prevent COVID-19 disease. Given the existing literature, the current study chooses temperature and air quality $\left(\mathrm{PM}_{2.5}\right)$ as indicators of COVID-19 spread in Spain regions. 
a
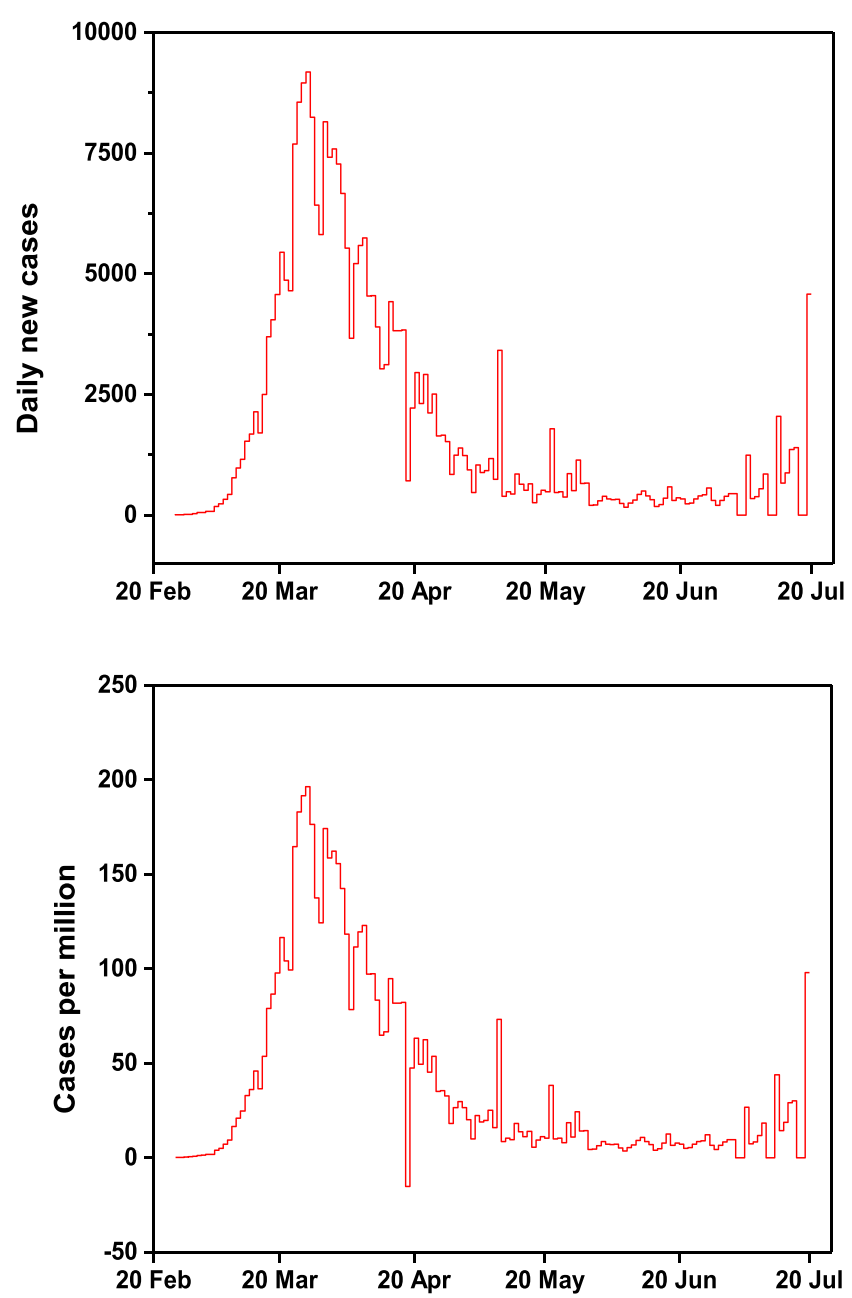
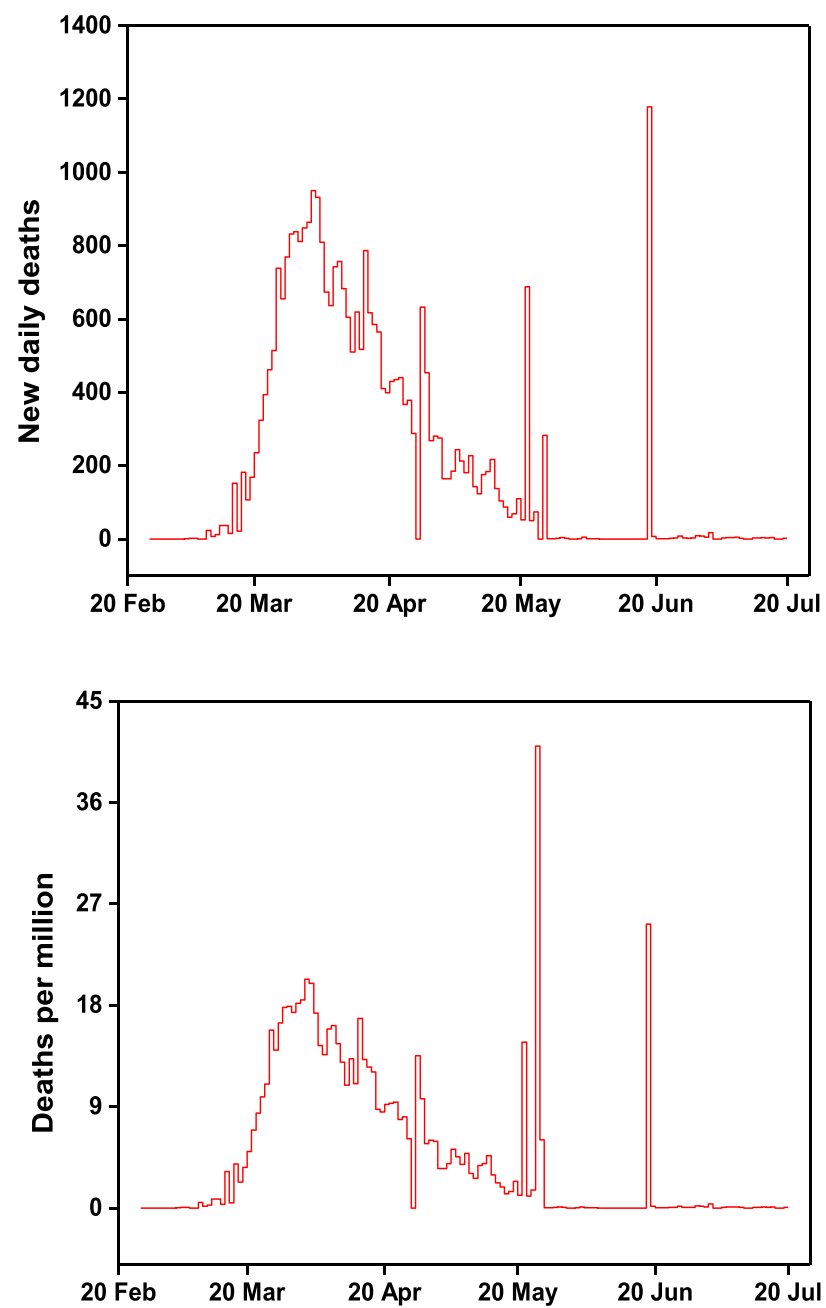

b

\section{COVID-19 Daily cases}

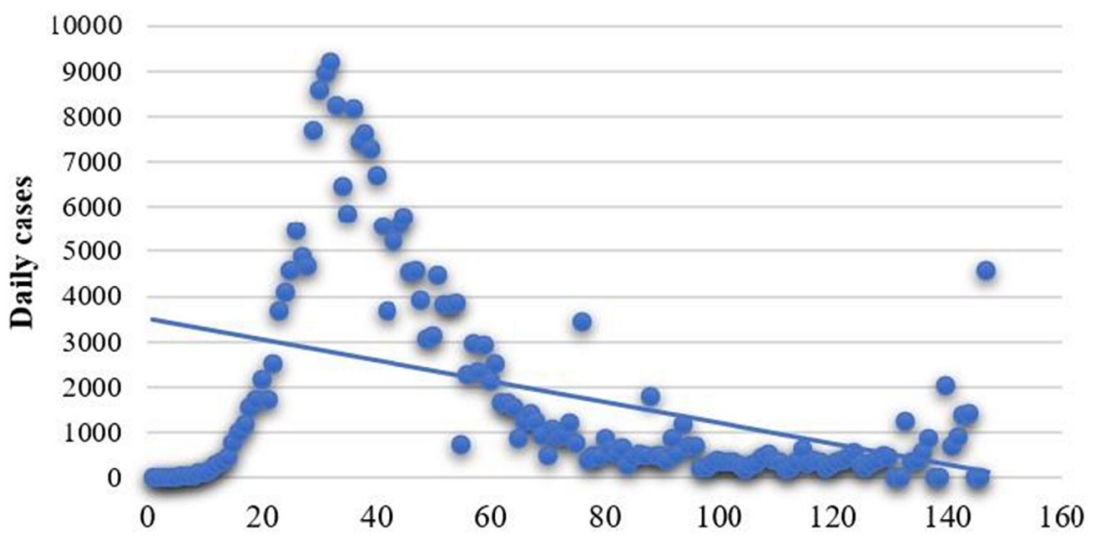

Date: Daily observations from February to 20 July 2020

Fig. 1 a COVID-19 outlook for Spain. Source: WHO (2020). b Scatterplot for COVID-19 new cases in Spain 
Fig. 2 COVID-19 variation across the four most affected regions of Spain

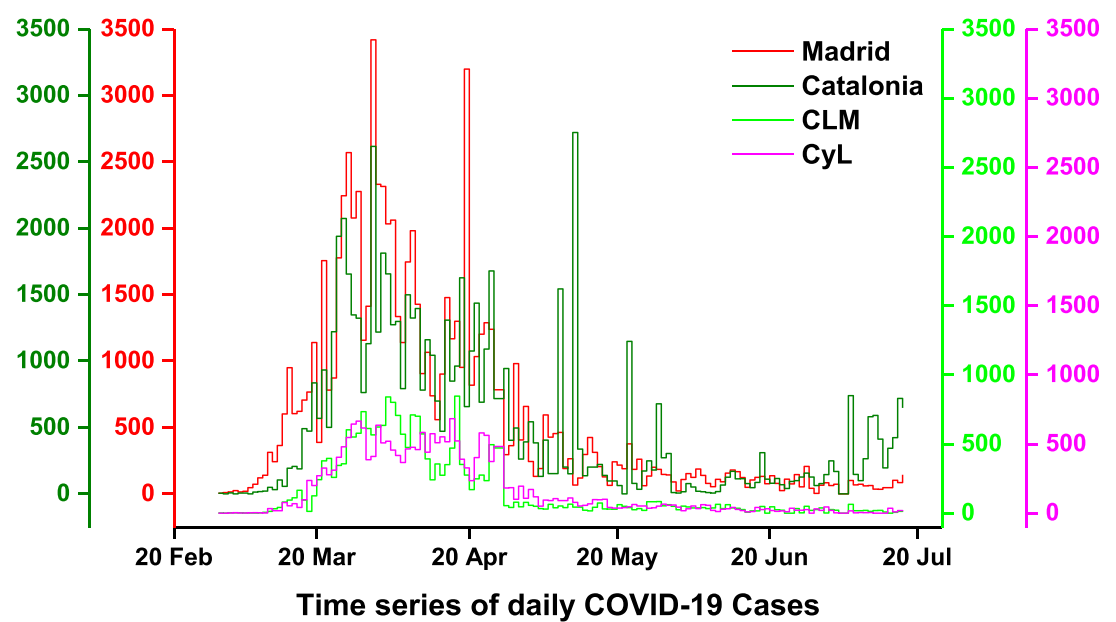

a

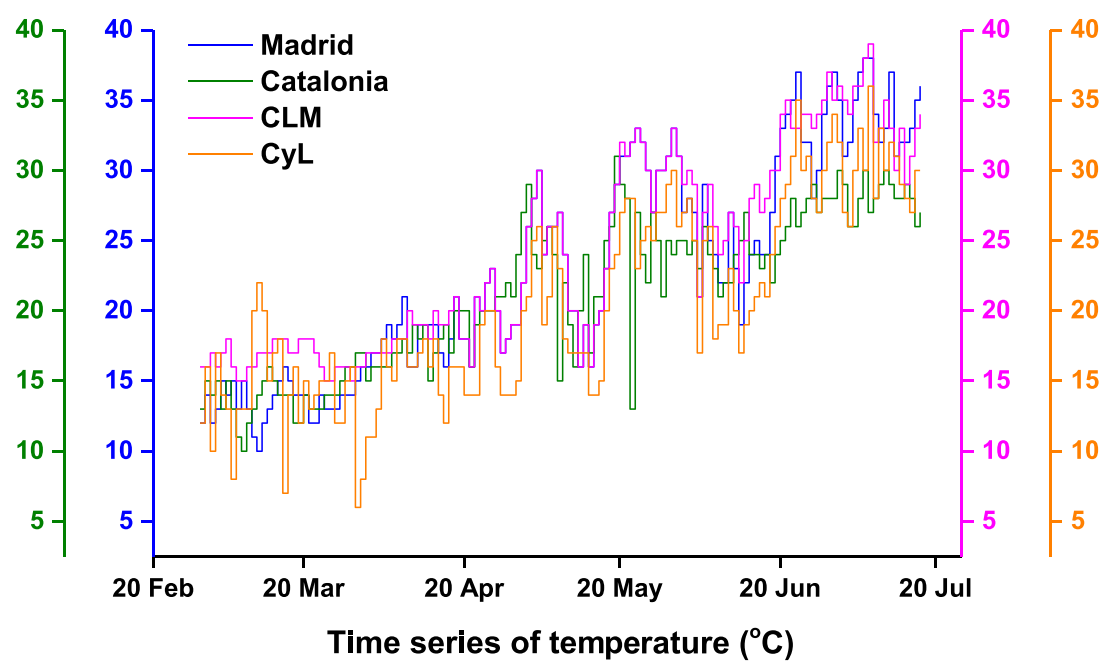

b

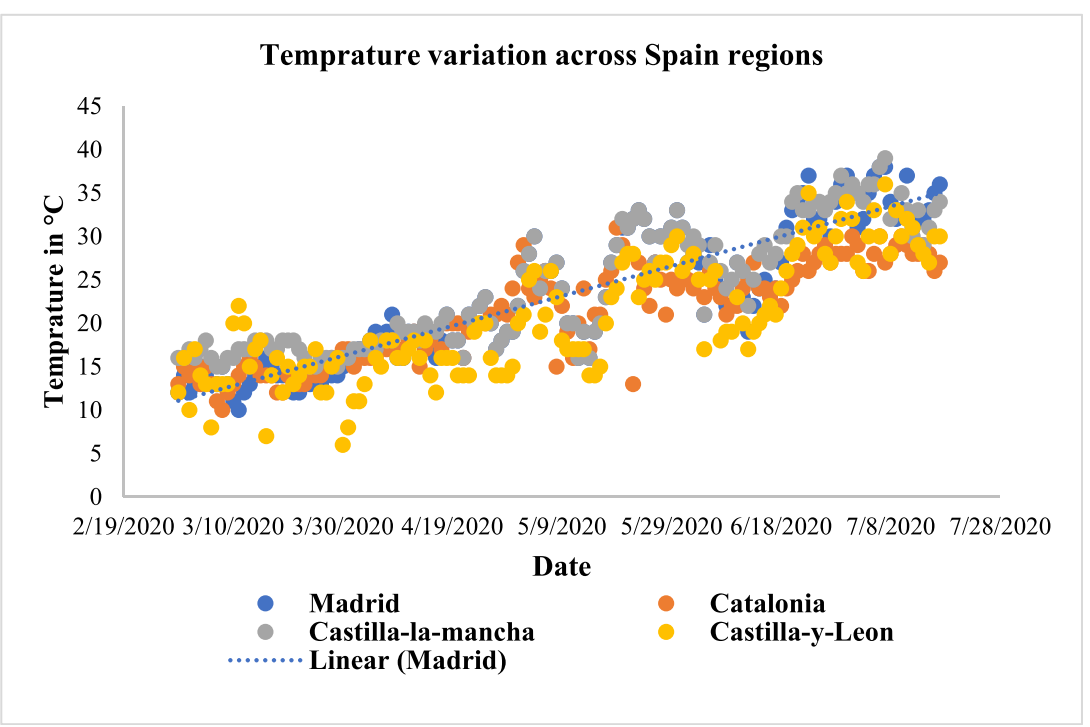


The current research mainly focuses on the research problem given as Does the COVID-19 outbreak correlates with climatology parameters (temperature and air quality) in Spain? To the best of the authors' knowledge, this is probably the first work to explore the association between climatology parameters with COVID-19 for the case of Spain. The climatology data are based on information between 29 February and 18 July 2020, in Spain, the duration of fast and peak outbreak of COVID-19 pandemic. However, the parameters were subjected from the top four most populated regions of Spain (Madrid, Catalonia, Castilla-La Mancha, and Castilla y Leon), which can result in infection prevalence and are more in the exposure to COVID-19 identified.

It is important to mention here that the theme and objective of the current study are in line with the scientific reasons and join the strand of recent literature. For instance, more recently, the literature based on meteorological parameters suggested that air quality, population density, temperature, and pollution significantly influence the COVID-19 infections spread in different regions of China and Turkey (Shi et al. 2020; Iqbal et al. 2020; Fareed et al. 2020). On the contrary, Jahangiri et al. (2020) concluded that weather and climate might not affect the COVID-19 spread in Iran. There is still a dearth of literature research regarding COVID-19 and weather parameters. The existing studies have mainly reported mixed findings regarding the determinants and causing factors of COVID-19. However, the effects of different environmental factors on the incidence of COVID-19 remain to be elucidated. The prime objective of this research is to unveil the effects of temperature and air quality $\left(\mathrm{PM}_{2.5}\right)$ with the daily COVID-19 cases in Spain.

To this end, the authors employ the detailed correlation analyses and panel data regression methods on the panel data of four profoundly affected regions of Spain.

The "Climatology and weather conditions in Spain" section describes the climatology and weather conditions in Spain. The "Materials and methods" section explains the data and methods with graphical analysis. The "Empirical results" section reports the empirical results with discussion and scientific reasons, while the "Conclusion" section concludes the paper.

\section{Climatology and weather conditions in Spain}

Currently, the major part of Spain population feels health and safety risks. During recent years, over 15 million people's health in Spain was adversely affected by just a few of the pollution paradoxes. Currently, the most severely affected areas due to COVID-19 are Madrid and Barcelona, but the regions of Andalusia, Extremadura, Castilla y León, and Castilla-La Mancha and Catalonia are also battling with high-risk levels.

The climate in Spain is extremely varied. There are five types of climate: the climate of the Atlantic coast, cold, humid, and rainy. Therefore, Spain is not always warm and sunny. However, if you exclude the north-facing coast, in much of Spain, the summer is hot, dry, and sunny. The average temperature ranges from 10 to $40{ }^{\circ} \mathrm{C}$.

Three primary pollutants plague Spain: nitrogen dioxide $\left(\mathrm{NO}_{2}\right), \mathrm{PM}_{10} / \mathrm{PM}_{2.5}$ particulate matter, and finally ozone, a pollutant linked to the others. According to Spain Health reports, over 17.5 million Spaniards were hospitalized in 2019. At the same time, the poor air quality and temperature were regarded as key factors to influence the health of the population. Meanwhile, the Ministry for Ecological Transition insists it is impossible to measure the effects on health with any precision. The rising level of health issues was started after economic recovery in 2015, due to burning of fossil fuels and non-renewable sources.

Among air quality indicators, nitrogen dioxide $\left(\mathrm{NO}_{2}\right)$ is a byproduct of combustion at high temperatures, for instance, in-car motors and electricity plants. The most affected regions with $\mathrm{NO}_{2}$ were Madrid, Catalonia, Barcelona, and Granada. A report indicated that Madrid's atmosphere contains more than $50 \%$ of $\mathrm{NO}_{2}$ emissions, particularly by diesel vehicles (Inventory of Contaminating Emissions). The problem with $\mathrm{PM}_{10} / \mathrm{PM}_{2.5}$ particulates is more than other pollutants. The $\mathrm{PM}_{2.5}$ particulate matter consists of dust, ash, soot, and similar substances produced by traffic as well as central heating systems, industry, construction, demolition works, but traffic can also be a source. It affected most parts of Granada, Madrid, Málaga, Castilla-La Mancha, and Asturias, Jaén province. Out of 126 big cities of Spain, 36 were affected due to ozone gas. Most affected areas were Madrid (Sierra Norte region severely hit in Madrid) from where the wind blows the ozone gas from the center to Castilla y León and Castilla-La Mancha. The more cars and pollution in the cities, the bigger the ozone problem in the outlying areas.

Breathing in polluted air affects our respiratory system and aggravates chronic respiratory diseases in several ways, e.g., asthma or COPD (chronic obstructive pulmonary disease) and vascular problems, such as strokes and heart attacks. The polluted particles such as $\mathrm{PM}_{10} / \mathrm{PM}_{2.5}$ can penetrate the human circulation, triggering inflammatory mechanisms that damage different organs. The worst affected are the lungs, the heart, and the blood vessels. In 2015, in Spain, there were 38,600 premature deaths, and 27,900 people were severely affected due to particulate pollution of air (European Environment Agency 2018).

Recently, due to COVID-19 crisis, implementation of lockdown restrictions adopted by states and the federal government has resulted in stopping of economic activities such as industrial projects, construction projects, and transportations observing the stagnant phase (Shakoor et al. 2020). Consequently, the levels of $\mathrm{NO}_{2}$ and $\mathrm{PM}_{2.5}$ particles of air contaminant have declined 64\% in major Spanish cities due to COVID-19 precaution measures. In Barcelona, the 
pollution decline to $83 \%$, and Madrid and València dropped the pollution level in the air by about $73 \%$ and $64 \% 1$.

\section{Materials and methods}

\section{Study area and data specification}

In this study, we collected daily data of the top four regions of Spain in COVID-19 infections. These regions include Castilla y Leon, Castilla-La Mancha, Catalonia, and Madrid, while the time of data ranges from 29 February to 17 July 2020 (European union 2020).According to World Bank records, Spain has a population of almost 47 million, with a population growth rate of $0.3 \%$ per year. The main reason behind selecting Spain is it is currently in the top ten world's most infected country ${ }^{2}$ in the world with 260,555 confirmed cases and 28,420 total deaths. The meteorological data, including daily average temperature (AT) and daily $\mathrm{PM}_{2.5}$ (a proxy of air quality) of each region, were retrieved from the World Air Quality organization (https://aqicn.org). However, the data for daily COVID new cases is accessed from the EL PAIIS: the global newspaper ${ }^{3}$ of Spain. The daily data consists of COVID-19 new confirmed cases, the average temperature in degree celsius $\left({ }^{\circ} \mathrm{C}\right)$, and real-time air quality as $\mathrm{PM}_{2.5}$.

Figure 1b illustrates the scatterplot for COVID-19 daily new cases with a trend line ${ }^{4}$. The scatterplot clearly shows that the COVID-19 transmission rate was high in March and April, then it suddenly reduced. The COVID-19 daily news cases in Madrid, Catalonia, Castilla-La Mancha, and Castilla y Leon, respectively, are shown in Fig. 2. We observe that Madrid and Catalonia (red and dark green lines) are the most affected regions of Spain, followed by Castilla-La Mancha and Castilla y Leon (green and pink lines).

Similarly, from Fig. 3a, we note that the highest fluctuation of daily temperature is recorded in Castilla-La Mancha and Madrid (pink and blue lines). From the scatterplot of temperature, we observe that Madrid and Castilla-La Manch have high temperature and more fluctuations. In the same line, we observe the $\mathrm{PM}_{2.5}$ from Fig. 4, and Madrid shows the highest level of fluctuation of $\mathrm{PM}_{2.5}$ while Catalonia and Castilla y Leon indicate the lowest level. From a graphical analysis, the authors observe that weather changes in Spain regions are similar to the COVID-19 fluctuations in Spain. Such facts and scientific reasons motivate the researchers to draw a more detailed analysis to attain our primary study objective.

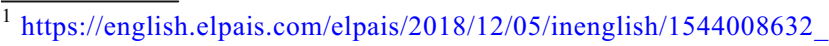
514634.html.

2 The figures are provided as of 18 July 2020. Spain is recording daily new cases of 2000 average.

${ }^{3} \mathrm{https}: / /$ elpais.com/ reports all kinds of health and other indicators data in Spain.

${ }_{4}^{4}$ Authors are grateful to reviewer 2 for this useful advice and suggestion.
}

Due to normality issues, all three variables are transformed into a natural logarithm. Table 1 shows the descriptive statistics of variables with and without log transformation. The summary statistics display that data is average, and there are no outliers in the panel data.

\section{Estimation strategy}

For empirical analysis, we use the step by step approach. For instance, first, we checked the normality by descriptive analysis (Table 1). Descriptive statistics are shown with and without log transformation. The descriptive is based on the panel data of the top four Spain regions in COVID-19. In the second step, we perform a detailed correlation analysis to check the co-movement between temperature, air quality, and COVID19 daily cases of Spain. In the next step, we normalized the data by transforming the variables into a natural logarithm.

Following the recent study of Tosepu et al. (2020), we further apply the Pearson correlation technique between three variables of COVID-19, temperature, and $\mathrm{PM}_{2.5}$ (Table 2). We further use the pairwise correlation analysis of Spearman correlation methods to examine the robustness between three variables of COVID-19, temperature, and $\mathrm{PM}_{2.5}$ (Table 3).

After performing the correlation analysis between our primary variables of interest, we utilize the panel regression to check if temperature and air quality exert pressure on COVID incidents of Spain. In doing so, we use panel regression, quantile regression, pooled OLS (robust Driscoll and Kraay standard errors), and fixed effects methods. The panel regression methods are employed on our baseline model given as

Covid $=f($ Temp, Air $)$

$\ln \operatorname{Covid}_{i, t}=\alpha_{o}+\beta_{1} \operatorname{Temp}_{i, t}+\beta_{2} \operatorname{Air}_{i, t}+\varepsilon_{i, t}$

In Eq. (2), the variables are used with log transformation, where $T e m p_{i, t}$ mentions the impact of daily average temperature, $A i r_{i, t}$ illustrates the effect of air quality, and $\varepsilon_{i, t}$ shows the error term.

\section{Empirical results}

\section{Main findings}

Table 1 shows the descriptive statistics for daily COVID19 cases, $\mathrm{PM}_{2.5}$, and temperature variables. During the study period (29 February 2020 to 17 July 2020), there were 260,555 COVID-19 confirmed cases in Spain. Temperatures ranged from 10 to $40{ }^{\circ} \mathrm{C}$, and $\mathrm{PM}_{2.5}$ ranged from 10 to 100 in the top four regions of Spain used in this research work. The average temperature and $\mathrm{PM}_{2.5}$ during this period were $25{ }^{\circ} \mathrm{C}$ and 45 , 
Fig. $4 \mathrm{PM}_{2.5}$ variation across Spain regions

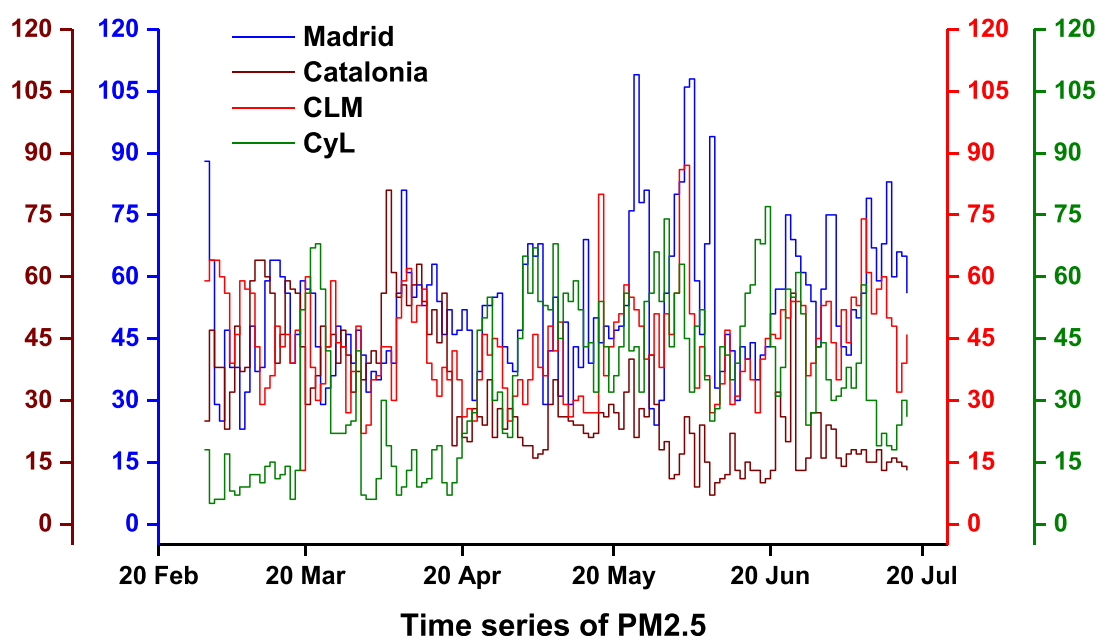

respectively. The mean concentrations of $\mathrm{PM}_{2.5}$, temperature, and COVID-19 were $341.95,39.98$, and 21.2, respectively.

Table 2 presents the coefficients of the Pearson correlation for all possible pairs of our variables of interest. The correlation between all the variables is not the same. The values of coefficients are $1\left(\mathrm{PM}_{2.5}\right.$ and temperature), 0.37 (COVID-19 and $\mathrm{PM}_{2.5}$ ), and $-0.3166^{*}$ (temperature and COVID-19), respectively. Our results show that temperature and COVID-19 variables tend to show a negative and significant direction, while COVID19 and $\mathrm{PM}_{2.5}$ show a positive and significant correlation. Table 3 presents results from Spearman's rank correlation among all pairs of variables. All the correlation value trends show similar values nearly the same to those obtained from Pearson correlation analysis. The values of coefficients are $1\left(\mathrm{PM}_{2.5}\right.$ and temperature), 0.0238 (COVID-19 and $\mathrm{PM}_{2.5}$ ), and $-0.3917^{*}$ (temperature and COVID-19), respectively.

Table 4 presents the results from competing regression models. We have employed three regression models for analysis: quantile regression, pooled OLS, and fixed effects regression model. Notably, coefficients of air quality $\left(\mathrm{PM}_{2.5}\right)$ are positive with significant values. The results suggest that fixed effects regression and pooled OLS provide similar coefficients for $\mathrm{PM}_{2.5}$, close in value $\left(0.210^{*}\right.$ and 0.3181$)$, whereas the quantile regression model presents a lower positive and significant value $\left(0.049^{*}\right)$ than the other two. Each $1 \%$ increase in $\mathrm{PM}_{2.5}$ results in an increase of $0.63 \%, 0.21 \%$, and $0.41 \%$ in COVID-19 cases, according to pooled OLS, quantile regression, and fixed effects regression, respectively.

Coefficients of the temperature are negative and significant in the case of all competing models, suggesting that there is no role of temperature in COVID-19 infections. Results showing a pattern of temperature, fixed effects regression, and pooled OLS provide similar coefficients for temperature, close in value $\left(-1.795 * * *\right.$ and $\left.-1.7816^{* *}\right)$, whereas the quantile regression model presents a bit larger negative value $(-2.644 * * *)$ than other two. Overall, the panel regression empirics imply that temperature may be negatively associated with the COVID-19 spread, and air quality may induce more infections in Spain.

\section{Discussion of analysis}

Our results are consistent with recent studies suggesting that lousy air quality leads to an increase in the number of new COVID-19 infections (Park et al. 2019). Temperature is not associated with the daily new COVID-19 infections and not helpful to slow down the spread of this disease, quite the

Table 1 Descriptive statistics

\begin{tabular}{llllllllll}
\hline Variables & Obs & Mean & S.Dev & Min & Max & p1 & p99 & Skew. & Kurt. \\
\hline COVID-19 & 560 & 341.948 & 513.348 & 0 & 3419 & 0 & 2331 & 2.517 & 10.458 \\
PM $_{2.5}$ & 560 & 39.977 & 18.227 & 5 & 109 & 6 & 87 & .375 & 3.251 \\
Temperature & 560 & 22.196 & 6.984 & 6 & 39 & 10 & 37 & .294 & 2.074 \\
LnCovid & 560 & 4.76 & 1.714 & 0 & 8.137 & .693 & 7.754 & -.404 & 2.74 \\
LnTemp & 560 & 3.048 & .327 & 1.792 & 3.664 & 2.303 & 3.611 & -.278 & 2.568 \\
LnPM $_{2.5}$ & 560 & 3.558 & .558 & 1.609 & 4.691 & 1.792 & 4.466 & -.994 & 3.775 \\
\hline
\end{tabular}

Note: Descriptive statistics are shown with and without log transformation. The descriptive is based on the panel data of top four Spain regions in COVID-19. Ln values show descriptive with log transformation 
Table 2 Pairwise correlation analysis (Pearson correlation)

\begin{tabular}{llll}
\hline Variables & LnCovid & LnPM $_{2.5}$ & LnTemp \\
\hline COVID-19 & 1 & & \\
Temperature & $-0.3166^{*}$ & 1 & \\
$\mathrm{PM}_{2.5}$ & $0.371^{* *}$ & $0.1926^{*}$ & 1 \\
\hline
\end{tabular}

Note: $*$ shows significance at the $5 \%$ level

opposite to the expectations of many experts and some earlier studies (Tosepu et al. 2020; Wang et al. 2020). The rise in temperature may reduce the COVID-19 outbreak, as indicated by the results of our correlation and regression analysis. The findings suggest that temperature may slow down the virus' effects or reduce its survival period in air and surface. Similar values obtained from multiple models add to the robustness of our results. Recent studies in China and Iran support our results indicating no evidence was found to support the COVID19 cases could decline when the weather becomes warmer (Xie and Zhu 2020; Jahangiri et al. 2020).

Previously, some studies reported that the temperature is the main factor in the survival and transmission of SARS-CoV and MERS-CoV diseases (Bi et al. 2007; Casanova et al. 2010; Chan et al. 2011; Tan et al. 2005; Van Doremalen et al. 2013). We compared our results with the main findings of these studies. Another study indicated that the optimum environmental temperature related to SARS cases was from 16 to $28{ }^{\circ} \mathrm{C}$ based on data from Hong Kong, Guangzhou, Beijing, and Taiyuan (Tan et al. 2005). Moreover, Bi et al. (2007) reported that temperature had a negative relationship with SARS transmission in Hong Kong and Beijing in 2003. Another laboratory study found that coronavirus on smooth surfaces was stable for over 5 days when the temperature was at 22-25 ${ }^{\circ} \mathrm{C}$ (Chan et al. 2011). In brief, most studies showed that there was an optimum temperature $\left(22-25^{\circ} \mathrm{C}\right)$ for coronavirus, and the high temperature was harmful to its viability. However, our findings could not observe an adverse effect of high temperature on COVID-19 infection. A possible reason may be that the study period starts in winter and ends in early summer, with a maximal mean temperature of $30^{\circ} \mathrm{C}$. Further laboratory studies also need to be conducted to determine the underlying mechanism.

Table 3 Pairwise correlation analysis (Spearman correlation)

\begin{tabular}{llll}
\hline Variables & LnCovid & LnPM $_{2.5}$ & LnTemp \\
\hline COVID-19 & 1 & & \\
Temperature & $-0.3917 *$ & 1 & \\
$\mathrm{PM}_{2.5}$ & 0.0238 & $0.1647^{*}$ & 1 \\
\hline
\end{tabular}

Note:* shows significance at the $5 \%$ level
Table 4 Panel regression empirics

\begin{tabular}{llll}
\hline Variables & Pooled OLS & Quantile regression & Fixed effects \\
\hline Temperature & $-1.7816^{* *}$ & $-2.644^{* * *}$ & $-1.795^{* * *}$ \\
& {$[2.480]$} & {$[-9.450]$} & {$[-8.930]$} \\
$\mathrm{PM}_{2.5}$ & $0.3181^{* *}$ & $0.049 * *$ & $0.210^{* *}$ \\
& {$[2.2100]$} & {$[0.300]$} & {$[1.600]$} \\
Constant & $9.0463^{* *}$ & $12.889^{* * *}$ & $9.472^{* * *}$ \\
& {$[3.570]$} & {$[13.790]$} & {$[13.240]$} \\
$R^{2}$ & 0.110 & 0.122 & 0.129 \\
Observations & 560 & 560 & 560 \\
\hline
\end{tabular}

Note: The symbols $*$, **, and $* * *$ denote the significance level at $10 \%$, $5 \%$, and $1 \%$, respectively. $t$-statistics of the corresponding coefficients are reflected in brackets

Our analysis of $\mathrm{PM}_{2.5}$ is similar to previous reports that suggested that the impact of delicate particulate matter only $1 \mu \mathrm{g}$ in $\mathrm{PM}_{2.5}$ has a positive and significant association with an increase in the COVID-19 spread (Wu et al. 2020b). Empirically data analyzed by Yao et al. (2020) suggested that the spatial correlation of $\mathrm{PM}_{10}$ and $\mathrm{PM}_{2.5}$ has a positive correlation with COVID19 cases and rate in China. Furthermore, the researchers suggested that pollution caused by the particulate matter influences the prognosis of the patients. Fattorini and Regoli (2020) analyzed the association of air quality and COVID-19 outbreak in Italy. They concluded that continuous exposure to environmental pollution $\left(\mathrm{PM}_{10}\right.$ and $\left.\mathrm{PM}_{2.5}\right)$ in Northern Italy is the primary cause of COVID-19 cases. Similarly, Shahzad et al. (2020) and Piazzalunga-Expert (2020) for the case of China, Italy, and India supported similar findings.

Keeping in touch with earlier literature (Amuakwa-Mensah et al. 2017), recent studies are focusing on how population size and population density affect both the current and future spread of COVID-19 disease (Jahangiri et al. 2020; Rocklöv and Sjödin 2020; Zhang et al. 2020).

However, it might be possible that the incidence rate of the infection depends on population density and other factors associated with warmer and drier weather (Byass 2020). It also needs to know why, to date, the epidemic has hit so hard several highly densely populated areas around the world, e.g., New York in the USA and Madrid metropolitan area in Spain and densely populated areas of Brazil, Italy, Germany, India, and so forth. These findings may be limited in application to a European country (Spain) due to its unique climate, social setup, and several other factors related to healthcare facilities and densely populated regions data. Nevertheless, the result provides a valuable perspective on climateinfectious-diseases-control studies. Since the outbreak of COVID-19 is still out of appropriate control in Spain at the moment, the data related to new infections and climate factors are in the process of formation. Additional studies at the end of this outbreak will be more helpful in understanding the role played by the climate factors in COVID-19 spread or control. 


\section{Conclusion}

This is probably the first article to investigate the correlations between average temperature, air quality, and COVID-19 in Spain population. The authors employed extensive panel data ranging from February to 17 July 2020 to report more recent and conclusive evidence. The present study utilizes correlation and panel regression methods to investigate the association between temperature, air quality, and COVID-19 across four regions of Spain with high infections. The empirics conclude that weather might be a significant factor in determining the incidence rate of COVID-19 in Spain. The correlation findings suggest that air quality may significantly increase the COVID-19 transmission with $0.37 \%$ in all regions of Spain.

On the contrary, the correlation empirics conclude that temperature may not induce the COVID-19 spread. Instead, it might act as a contributory factor to reduce its transmission rate with $0.39 \%$. Interestingly, all of the panel regression findings support the correlation results and argue that temperature may reduce the COVID-19 spread. More precisely, $1{ }^{\circ} \mathrm{C}$ change in temperature may reduce the COVID-19 spread with 1 to 2 new cases, while the increase in air quality may enhance it from 0.5 to $0.21 \%$ influence. The findings of this work are very innovative and support the narrative of a few existing studies, that temperature negatively affects the COVID-19 daily infections. The results of this work can assist the policymakers in suppressing COVID-19 disease in Spain for humanity-saving efforts.

Recently, the Spanish health authorities have warned that young people are being admitted into intensive care as acute cases of COVID-19, which is very alarming and dangerous for Spain. In July 2020, Spain is facing an average daily 1200 to 1500 new cases of COVID-19, even with the young and older population. The authors argue that COVID-19 will be a window for research for many decades, and future research will guide us more about its causes, treatment, and adverse effects.

Acknowledgments We are grateful to the editor and anonymous referees for valuable comments and helpful suggestions.

Funding information This work was financially supported by the National Natural Science Foundation of China: Grant Numbers 71503001, 71974001; Provincial Natural Science Research Project in Anhui Province: Grant Number KJ2019A0649.

Data availability The datasets used during the current study are available on request.

\section{Compliance with ethical standards}

Conflict of interest The authors declare that they have no competing interests.
Abbreviations COVID-19, coronavirus disease 2019; AT, daily average temperature; $\mathrm{PM}_{2.5}$, air quality indicator

\section{References}

Amuakwa-Mensah F, Marbuah G, Mubanga M (2017) Climate variability and infectious diseases nexus: evidence from Sweden. Infect Dis Model 2:203-217. https://doi.org/10.1016/j.idm.2017.03.003

Anderson RM, Heesterbeek H, Klinkenberg D, Hollingsworth TD (2020) How will country-based mitigation measures influence the course of the COVID-19 epidemic? Lancet 395:931-934

Bi P, Wang J, Hiller J (2007) Weather: driving force behind the transmission of severe acute respiratory syndrome in China? Intern Med J 37:550-554. https://doi.org/10.1111/j.1445-5994.2007.01358.x

Byass P (2020) Eco-epidemiological assessment of the COVID-19 epidemic in China, January-February 2020. Glob Health Action 13: 1760490. https://doi.org/10.1080/16549716.2020.1760490

Casanova LM, Jeon S, Rutala WA, Weber DJ, Sobsey MD (2010) Effects of air temperature and relative humidity on coronavirus survival on surfaces. Appl Environ Microbiol 76:2712-2717. https://doi.org/10. 1128/AEM.02291-09

Chan K, Peiris J, Lam S, Poon L, Yuen K, Seto W $(2011,2011)$ The effects of temperature and relative humidity on the viability of the SARS coronavirus. Adv Virol. https://doi.org/10.1155/2011/ 734690

Chen B, Liang H, Yuan X, Hu Y, Xu M, Zhao Y, et al (2020) Roles of meteorological conditions in COVID-19 transmission on a worldwide scale. medRxiv

Dalziel BD, Kissler S, Gog JR, Viboud C, Bjørnstad ON, Metcalf CJE, Grenfell BT (2018) Urbanization and humidity shape the intensity of influenza epidemics in U.S. cities. Science 362:75-79

Eccles R (2002) An explanation for the seasonality of acute upper respiratory tract viral infections. Acta Otolaryngol 122(2):183-191

Epstein PR (2001) West Nile virus and the climate. J Urban Health 78: 367-371

European Environment Agency (2018) https://english.elpais.com/elpais/ 2018/12/05/inenglish/1544008632_514634.html. [Online] Available at https://english.elpais.com/elpais/2018/12/05/inenglish/ 1544008632_514634.html [Accessed 25th July 2020].

European Union (2020) COVID-19 coronavirus data. [Online] Available at https://data.europa.eu/euodp/en/data/dataset/covid-19coronavirus-data [Accessed 25th July 2020].

Fareed Z, Iqbal N, Shahzad F, Shah SGM, Zulfiqar B, Shahzad K, Hashmi SH, Shahzad U (2020) Co-variance nexus between COVID-19 mortality, humidity, and air quality index in Wuhan, China: new insights from partial and multiple wavelet coherence. Air Qual Atmos Health 13:673-682. https://doi.org/10.1007/ s11869-020-00847-1

Fattorini D, Regoli F (2020) Role of the atmospheric pollution in the Covid-19 outbreak risk in Italy. medRxiv

Gorbalenya AE (2020) Severe acute respiratory syndrome-related coronavirus-the species and its viruses, a statement of the Coronavirus Study Group. BioRxiv, 1-15. https://doi.org/10.1101/ 2020.02.07.937862

Iqbal N, Fareed Z, Shahzad F, He X, Shahzad U, Lina M (2020) The nexus between COVID-19, temperature and exchange rate in Wuhan city: new findings from partial and multiple wavelet coherence. Sci Total Environ 729:138916. https://doi.org/10.1016/j. scitotenv.2020.138916

Jahangiri M, Jahangiri M, Najafgholipour M (2020) The sensitivity and specificity analyses of ambient temperature and population size on the transmission rate of the novel coronavirus (COVID-19) in different provinces of Iran. Sci Total Environ 728:138872 
Kudo E, Song E, Yockey LJ, Rakib T, Wong PW, Homer RJ, Iwasaki A (2020) Low ambient humidity impairs barrier function and innate resistance against influenza infection Proc. Natl Acad Sci 116(22): 10905-10910

Li Q, Guan X, Wu P, Wang X, Zhou L, Tong Y, Ren R, Leung KSM, Lau EHY, Wong JY, Xing X, Xiang N, Wu Y, Li C, Chen Q, Li D, Liu T, Zhao J, Liu M, Tu W, Chen C, Jin L, Yang R, Wang Q, Zhou S, Wang R, Liu H, Luo Y, Liu Y, Shao G, Li H, Tao Z, Yang Y, Deng Z, Liu B, Ma Z, Zhang Y, Shi G, Lam TTY, Wu JT, Gao GF, Cowling BJ, Yang B, Leung GM, Feng Z (2020) Early transmission dynamics in Wuhan, China, of novel coronavirus-infected pneumonia. N Engl J Med 382:1199-1207

Lipsitch M, Viboud C (2009) Influenza seasonality: lifting the Fog. PNAS 106(10):3645-3646. https://doi.org/10.1073/pnas. 0900933106

Lowen AC, Steel J (2014) Roles of humidity and temperature in shaping influenza seasonality. J Virol 88(14):7692-7695

Lowen AC, Mubareka S, Steel J, Palese P (2007) Influenza virus transmission is dependent on relative humidity and temperature. PLoS Pathog 3(10):1470-1476. https://doi.org/10.1371/journal.ppat. 0030151

Ministry of Health Spain (2020) Novel coronavirus disease, COVID-19 [Online] https://www.mscbs.gob.es/profesionales/saludPublica/ ccayes/alertasActual/nCov-China/home.htm. Accessed 15 July 2020

Mohsen A, Sharifi A, Dorosti S, Ghoushchi SJ, Ghanbari N (2020) Investigation of effective climatology parameters on COVID-19 outbreak in Iran. Sci Total Environ 729:138705. https://doi.org/10. 1016/j.scitotenv.2020.138705

Mostafa H, Hopke PK, Jonidi A, Shahsavani A (2020) A letter about the airborne transmission of SARS-CoV-2 based on the current evidence. Aerosol Air Qual Res 20:911-914

Oliveiros B, Caramelo L, Ferreira NC, Caramelo F (2020) Role of temperature and humidity in the modulation of the doubling time of COVID-19 cases. medRxiv. https://doi.org/10.1101/2020.03.05. 20031872

Park JE, Son WS, Ryu Y, Choi SB, Kwon O, Ahn I (2019) Effects of temperature, humidity, and diurnal temperature range on influenza incidence in a temperate region. Influenza Other Resp 14(1):11-18. https://doi.org/10.1111/irv.12682

Piazzalunga-Expert A (2020) Evaluation of the potential relationship between particulate matter (PM) pollution and COVID-19 infection spread in Italy

Rocklöv J, Sjödin H (2020) High population densities catalyze the spread of COVID-19. J Travel Med 27:1-2. https://doi.org/10.1093/jtm/ taaa038

Shakoor A, Chen X, Farooq TH (2020) Fluctuations in environmental pollutants and air quality during the lockdown in the USA and China:two sides of COVID-19 pandemic. Air Qual Atmos Heal. https://doi.org/10.1007/s11869-020-00888-6

Shahzad F, Shahzad U, Fareed Z, Iqbal N, Hashmi SH, Ahmad F (2020) Asymmetric nexus between temperature and COVID-19 in the top ten affected provinces of China: a current application of quantile on quantile approach. Sci Total Environ 736:139115. https://doi.org/ 10.1016/j.scitotenv.2020.139115

Shaman J, Kohn M (2009) Absolute humidity modulates influenza survival, transmission, and seasonality. Proc Natl Acad Sci U S A 106(9):3243-3248. https://doi.org/10.1073/pnas.0806852106
Shi P, Dong Y, Yan H, et al (2020) Impact of temperature on the dynamics of the COVID-19 outbreak in China. Sci Total Environ 728: 138890. https://doi.org/10.1016/j.scitotenv.2020.138890

Steel J, Palese P, Lowen AC (2011) Transmission of a 2009 pandemic influenza virus shows sensitivity to temperature and humidity similar to that of an H3N2 seasonal strain. J Virol 85(3):1400-1402. https://doi.org/10.1128/JVI.02186-10

Tamerius JD, Shaman J, Alonso WJ, Bloom-Feshbach K, Uejio CK, Comrie A, Viboud C (2013) Environmental predictors of seasonal influenza epidemics across temperate and tropical climates. PLoS Pathog 9:e1003194

Tan J, Mu L, Huang J, Yu S, Chen B, Yin J (2005) An initial investigation of the association between the SARS outbreak and weather: with the view of the environmental temperature and its variation. J Epidemiol Community Health 59:186-192. https://doi.org/10.1136/jech.2004. 020180

Tellier R (2009) Aerosol transmission of influenza A virus: a review of new studies. J R Soc Interface 6(suppl 6):S783-S790. https://doi. org/10.1098/rsif.2009.0302.focus

Tosepu R, Gunawan J, Savitri D et al (2020) Correlation between weather and Covid-19 pandemic in Jakarta, Indonesia. Sci Total Environ 725:138436. https://doi.org/10.1016/j.scitotenv.2020.138436

Van Doremalen N, Bushmaker T, Munster V (2013) Stability of Middle East respiratory syndrome coronavirus (MERS-CoV) under different environmental conditions. Eurosurveillance 18, 20590. http:// www.eurosurveillance.org/ViewArticle.aspx? ArticleId $=20590$. Accessed 15 April 2020

Wang J, Tang K, Feng K, Lv W (2020) High temperature and high humidity reduce the transmission of COVID-19. Available at SSRN 35517672020

WHO (2020) Coronavirus disease 2019 (COVID-19) Situation Report;88.

Wu F, Zhao S, Yu B, Chen Y, Wang W, Song Z, Hu Y, Tao Z, Tian J, Pei Y, Yuan M, Zhang Y, Dai F, Liu Y, Wang Q, Zheng J, Xu L, Holmes EC, Zhang Y (2020a) A new coronavirus associated with human respiratory disease in China. Nature 579(7798):265-269. https://doi.org/10.1038/s41586-020-2008-3

Wu X, Nethery RC, Sabath BM, Braun D, Dominici F (2020b) Exposure to air pollution and COVID-19 mortality in the United States. medRxiv.

Xie J, Zhu Y (2020) Association between ambient temperature and COVID-19 infection in 122 cities from China. Sci. Total Environ. 138201.

Yao Y, Pan J, Wang W, Liu Z, Kan H, Meng X, Wang W (2020) Spatial correlation of particulate matter pollution and death rate of COVID19. medRxiv.

Yuan J, Yun H, Lan W, Wang W, Sullivan SG, Jia S, Bittles AH (2006) A climatologic investigation of the SARS-CoV outbreak in Beijing. China Am J Infect Control 34:234-236

Yueling MA, Zhao Y, Liu J, He X, Wang B, Shihua F, Yan J, Jingping N, Zhou J, Luo B (2018) Effects of temperature variation and humidity on the death of COVID-19 in Wuhan, China. Sci Total Environ 724: 138226. https://doi.org/10.1016/j.scitotenv.2020.138226

Zhang X, Liu H, Tang H, Zhang, M, Yuan X, Shen X (2020) The effect of population size for pathogen transmission on prediction of COVID19 pandemic spre

Publisher's note Springer Nature remains neutral with regard to jurisdictional claims in published maps and institutional affiliations. 